CLINICAL STUDY

\title{
Differences in the insulin tolerance test in patients with brain damage depending on posture
}

\author{
A Kopczak, F von Rosen ${ }^{1}$, C Krewer, H J Schneider ${ }^{2}$, G K Stalla ${ }^{3}$ and M Schneider \\ Schön Klinik Bad Aibling, Kolbermoorer Straße 72, 83043 Bad Aibling, Germany, ${ }^{1}$ Schön Klinik Bad Staffelstein, Am Kurpark 11, 96231 \\ Bad Staffelstein, Germany, ${ }^{2}$ University Hospital Innenstadt, Ludwig-Maximilians-University, Ziemsenstraße 1, 80336 Munich, Germany \\ and ${ }^{3}$ Clinical Endocrinology Group, Max Planck Institute of Psychiatry, Kraepelinstraße 10, 80804 Munich, Germany \\ (Correspondence should be addressed to M Schneider; Email: mschneider@schoen-kliniken.de)
}

\begin{abstract}
Objective: The insulin tolerance test (ITT) is the gold standard for the diagnosis of GH deficiency (GHD) and hypocortisolism. As hypopituitarism is a common disorder after traumatic brain injury (TBI) and subarachnoid hemorrhage (SAH), the test is increasingly used in patients with pre-existing brain damage.

Design: A cross-sectional, observational study.

Methods: Fifty-six patients (41 TBI and $15 \mathrm{SAH})$ were tested with the ITT $(0.15 \mathrm{IE} / \mathrm{kg}$ body weight, mean glucose $33 \mathrm{mg} / \mathrm{dl}$ ). In 38 patients, the test was performed in a supine position; the other 18 patients were in a sitting position during the ITT.

Results: Hypocortisolism and GHD were more often diagnosed in a supine than in a sitting position (hypocortisolism: $55.3 \%$ supine versus $0 \%$ sitting, $P<0.0001$; GHD: $42.1 \%$ supine versus $11.1 \%$ sitting, $P=0.03)$. Patients in a sitting position suffered more often from symptoms such as tachycardia $(61.1 \%$ sitting versus $15.8 \%$ supine, $P=0.001)$, trembling $(22.2 \mathrm{vs} 7.9 \%$, NS), and sweating $(66.7$ vs $28.9 \%, P=0.007)$. There were no significant differences between the groups in drowsiness $(72.2 \%$ sitting versus $65.8 \%$ supine, NS), dizziness (44.4 vs $44.7 \%$, NS), and fatigue (33.3 vs $15.8 \%$, NS). Because of somnolence, the hypoglycemic state could only be stopped with i.v. administration of glucose in 25 supine patients $(66 \%)$. In contrast, none of the 18 patients $(0 \%)$ tested in a sitting position got somnolent or was in need of i.v. application of glucose $(P<0.001)$.

Conclusions: In patients with brain injury, posture might affect rates of diagnosing GHD and hypocortisolism and sympathetic symptoms in the ITT. These findings are exploratory and need replication in a standardized setting.
\end{abstract}

European Journal of Endocrinology 164 31-36

\section{Introduction}

Hypopituitarism is a common complication after traumatic brain injury (TBI) and subarachnoid hemorrhage (SAH) (1-5). As the insulin tolerance test (ITT) is regarded as the gold standard to diagnose disorders of the hypothalamic-pituitary-adrenal axis (6), the test is more often used in patients with brain damage. Hypoglycemia ( $<40 \mathrm{mg} / \mathrm{dl}$ or $2.2 \mathrm{mmol} / \mathrm{l}$ blood glucose level respectively) induced by i.v. application of insulin increases stress hormones such as ACTH, cortisol, and GH. Even though the ITT is used since the 1960s $(7,8)$, there is no published detailed standard operating procedure (SOP) concerning the posture for the test.

Recently, Kokshoorn et al. (9) compared 14 studies with 913 patients after TBI and reported a large variation in the prevalence rates of hypopituitarism. Methodological issues and differences were identified as possible reasons for the high variation. The ITT was still discussed as gold standard, but Kokshoorn et al. outlined the low number of patients with brain damage tested with the ITT.

Performing a screening program for patients after TBI or SAH, patients were further tested with the ITT. Hereby, we revealed different symptoms and test results in the ITT depending on posture, which are noteworthy to be reported. In this analysis, we aimed at comparing the effects of posture in the ITT on diagnosing hypocortisolism and GH deficiency (GHD) and on side effects in a cross-sectional, observational study.

\section{Subjects and methods}

\section{Subjects}

Data from 56 patients (33 men, 23 women, age 20-64 years, mean age 42 years) from the Schön Klinik Bad 
Aibling, Bad Aibling, Germany, were sampled from 2006 to 2009. The patients gave informed, written consent to participate in the ITT. For patients who were not able to understand the whole significance and character of the study, consent was provided by a legally accepted representative. The ITT was part of the study to determine the prevalence of pituitary deficiency in the chronic phase in 509 patients after TBI and SAH, in which 41 patients with TBI and 15 patients with SAH were further tested with the ITT. The study was approved by the ethics committee of the Bavarian physicians' chamber in Munich.

Inclusion criteria were TBI of all grades, SAH, a modified Rankin scale (MRS) of 0-3 (0, no symptoms; 1 , no substantial disability despite symptoms; 2 , slight disability; and 3, moderate disability) (10), age of 18-65 years, and a body mass index (BMI) from 17 to $30 \mathrm{~kg} / \mathrm{m}^{2}$. Patients with glucocorticoid therapy within 3 weeks or GH treatment within 12 months, with preexisting pituitary diseases, history of cranial irradiation, severe cardiac, renal and hepatic diseases, sepsis, severe psychiatric disease or substance abuse, treatment with anabolic substances, participation in other clinical studies, pregnancy, and contraindications to ITT (coronary heart disease or known epilepsy) were excluded. If the seizure appeared within the first $24 \mathrm{~h}$ after brain damage, the ITT was performed at least 6 months after the epileptic seizure.

Time between brain injury and ITT was between 1 month and 13 years (mean time 2 years). From 2006 to 2007,38 patients were tested supine. Patients with conspicuous test results $(n=21)$ were referred to an endocrinologist. Twelve patients were treated at the Max Planck Institute of Psychiatry in Munich, (Endocrinology Group). Retesting of eight patients with insufficient increase in GH $(<3 \mu \mathrm{g} / \mathrm{l}$ or $<0.140 \mathrm{nmol} / \mathrm{l}$ respectively) or cortisol $(<18 \mu \mathrm{g} / \mathrm{dl}$ or $<497 \mathrm{nmol} / \mathrm{l}$ respectively) in a sitting position in the Max Planck Institute of Psychiatry could not confirm our diagnosis of GHD or hypocortisolism in these patients. Discussing the possible reasons for the different test results, we compared both ways of performing the ITT in the Max Planck Institute, Munich, Endocrinology Group, and in the Schön Klinik Bad Aibling. Hereby, we discovered that patients were tested in the Max Planck Institute for environmental reasons in a sitting position, whereas patients were tested supine in the Schön Klinik Bad Aibling. Therefore, we changed our testing position in the Schön Klinik Bad Aibling for the ITT from a supine into a sitting position. Since September 2008, 18 patients were tested in a sitting position. Both groups were not different in mean age, MRS, BMI, and lowest blood glucose (Table 1). Because of a possible and often occurring secondary impairment, the initial GCS does not always reflect the severity of illness. Therefore, we used the MRS to describe the more important long-term disability.
Table 1 Subject characteristics. Means \pm s.D.

\begin{tabular}{lll}
\hline & Supine & Sitting \\
\hline$n$ & 38 & 18 \\
$\mathrm{TBI}$ & 27 & 14 \\
$\mathrm{SAH}$ & 11 & 4 \\
$\mathrm{Sex}$ & $22 \mathrm{M}, 16 \mathrm{~F}$ & $11 \mathrm{M}, 7 \mathrm{~F}$ \\
$\mathrm{Age}$ & $42 \pm 14$ & $40 \pm 14$ \\
$\mathrm{BMI}$ & $25.16 \pm 3.65$ & $24.17 \pm 4.62$ \\
$\mathrm{MRS}$ & $3 \pm 2$ & $3 \pm 1$ \\
$\mathrm{MRS}_{\text {ITT }}$ & $1 \pm 1$ & $1 \pm 1$ \\
$\mathrm{BG}_{\min }$ & $32 \pm 5$ & $35 \pm 8$ \\
\hline
\end{tabular}

$\mathrm{BG}_{\min }$, minimal blood glucose; $\mathrm{BMI}$, body mass index; $\mathrm{MRS}$, modified Rankin scale at admittance to hospital; MRS ${ }_{\text {ITT }}$, modified Rankin scale at ITT; TBI, traumatic brain injury; $\mathrm{SAH}$, subarachnoid hemorrhage.

\section{Hormonal and clinical assessments}

Because of the diurnal rhythm of ACTH and cortisol, the ITT was performed in the morning (between 0800 and $0845 \mathrm{~h}$ ). Patients were fasting since $2200 \mathrm{~h}$ the day before. Blood was drawn by an i.v. line. About $15 \mathrm{~min}$ after setting the i.v. cannula, basal hormones and fasting cortisol (normal range 5-25 $\mu \mathrm{g} / \mathrm{dl}$ or $138-690 \mathrm{nmol} / \mathrm{l}$ respectively) were measured. For IGF1 measurement, the age-dependent SDS was calculated according to Brabant et al. (11).

After insulin dose of $0.15 \mathrm{IE} / \mathrm{kg}$ body weight was applied (Insuman Rapid $40 \mathrm{IU} / \mathrm{ml}$, Sanofi-Aventis, Frankfurt on the Main, Germany), blood sugar was measured regularly with a B. Braun Omnitest Plus (Melsungen, Germany) at least every $15 \mathrm{~min}$ in the first hour of the test. In most cases, $30 \mathrm{~min}$ after i.v. insulin injection, the blood sugar level dropped to $40 \mathrm{mg} / \mathrm{dl}(2.2 \mathrm{mmol} / \mathrm{l})$ or the patient suffered from typical symptoms of hypoglycemia for at least $15 \mathrm{~min}$. GH and cortisol were measured after $0,30,45,90$, and $120 \mathrm{~min}$ after measuring the lowest blood sugar level. Patients with persisting high blood sugar levels and lack of symptoms were treated with a second insulin dose depending on the blood sugar level.

Typical symptoms of hypoglycemia such as hunger, tachycardia, trembling, sweating, dizziness, fatigue, loss of vigilance, heat sensations, and others declared by the patients were recorded. After achieving the lowest possible blood sugar level (range $17-47 \mathrm{mg} / \mathrm{dl}$ or $0.9-2.6 \mathrm{mmol} / \mathrm{l}$ respectively; mean $33 \mathrm{mg} / \mathrm{dl}$ or $1.8 \mathrm{mmol} / \mathrm{l}$ respectively), the hypoglycemic state was interrupted by food intake. In severe cases of somnolence ( 25 supine patients, no sitting patient), an i.v. solution of $20 \%$ glucose had to be administered.

\section{Hormone measurements}

Blood was centrifuged at $3000 \mathrm{~g}$ for $10 \mathrm{~min}$, and the serum was stored at $-20^{\circ} \mathrm{C}$ until further processing. $\mathrm{GH}$ and IGF1 were measured by chemiluminescence with the Nichols Advantage System (Nichols Institute Diagnostics, San Clemente, CA, USA) until February 
2006 and later by the Immulite 2000 (Siemens Healthcare Diagnostics GmbH, Eschborn, Germany). As GH standard, the WHO NIBSC 2nd IS 98/574 was used, which offers a measurement range with the Immulite test from 0.05 to $40 \mu \mathrm{g} / \mathrm{l}(0.0023-1.86 \mathrm{nmol} / \mathrm{l})$.

Blood sugar was measured at once with the B. Braun Omnitest Plus, which measures the capillary blood glucose level via glucose oxidase reaction from 10 to $600 \mathrm{mg} / \mathrm{dl}(0.6-33.3 \mathrm{mmol} / \mathrm{l})$. For dual control, serum blood glucose was also measured in our local laboratory with the Hitachi 912 automatic analyzer from Roche via hexokinase reaction (measurement range: $2-750 \mathrm{mg} / \mathrm{dl}$ or $0.1-41.6 \mathrm{mmol} / \mathrm{l}$ respectively).

For the measurement of cortisol, the Elecsys 1010 from Roche was applied, which uses the electrochemiluminescence immunoassay (ECLIA) method to quantify cortisol levels from 0.018 to $63.4 \mu \mathrm{g} / \mathrm{dl}$ (0.5-1750 nmol/l).

\section{Statistical analyses}

To test for the significance between groups, the unpaired two-tailed Student's $t$-test was used for age and BMI; the Mann-Whitney $U$ test was applied for the MRS. Pearson's $\chi^{2}$ and Fisher's exact tests were used to compare the relationship between male and female in both groups and the prevalence of GHD and hypocortisolism respectively in both groups. Differences in declaring the symptoms such as tachycardia, sweating, heat sensations, drowsiness, dizziness, hunger, and fatigue were assessed by Pearson's $\chi^{2}$ test and also by Fisher's exact test for trembling and for i.v. application of glucose (IBM SPSS Statistics 17.0, IBM Corp., NY, USA). Peak cortisol levels and GH levels in the ITT were analyzed with SPSS 17.0 and visualized within box plots diagrams; data such as median, minimum, maximum, first quartile (25th percentile), and third quartile (75th percentile) were determined for patients tested in a sitting and in a supine position. Data such as lowest blood glucose are displayed as mean \pm s.D.

\section{Results}

\section{Endocrine insufficiency}

We detected hypocortisolism (peak cortisol $<18 \mu \mathrm{g} / \mathrm{dl}$ or $<497 \mathrm{nmol} / \mathrm{l}$ respectively) in 21 patients $(37.5 \%)$ after TBI and SAH (21 of 38 patients $(55.3 \%)$ tested supine and 0 of 18 patients $(0 \%)$ tested in a sitting position, $P<0.0001$ ) and GHD (peak GH $<3 \mu \mathrm{g} / \mathrm{l}$ or $<0.140 \mathrm{nmol} / \mathrm{l}$ respectively) in 18 patients $(32.1 \%)$ after TBI and SAH (16 of 38 patients $(42.1 \%)$ tested supine and 2 of 18 patients $(11.1 \%)$ tested in a sitting position, $P=0.03)$.

In none of the eight patients with hypocortisolism or GHD retested in a sitting position at the Department of Clinical Endocrinology, MPI of Psychiatry, Munich,
Table 2 Retesting of previous corticotropic or somatotropic insufficient patients.

\begin{tabular}{lccc}
\hline Subject & $\begin{array}{c}\text { GH peak } \\
\text { retest sitting } \\
\text { (previous } \\
\text { supine) }(\mu \mathrm{g} / \mathrm{l})\end{array}$ & $\begin{array}{c}\text { Cortisol peak } \\
\text { retest sitting } \\
\text { (previous } \\
\text { supine) }(\mu \mathrm{g} / \mathrm{dl})\end{array}$ & $\begin{array}{c}\text { Time to } \\
\text { retesting } \\
\text { (months) }\end{array}$ \\
\hline A & $10.7(0.4)$ & $21.3(15.4)$ & 20 \\
B & $22.7(0.2)$ & $22.2(13.8)$ & 5 \\
C & $8.73(4.3)$ & $19.9(14.1)$ & 10 \\
D & $14(0.1)$ & $24.8(14.2)$ & 6 \\
E & $19.9(0.1)$ & $22.3(10.2)$ & 16 \\
F & $15(0.1)$ & $24.4(12.9)$ & 5 \\
G & $20(0.6)$ & $24.3(13.1)$ & 6 \\
H & $5.1(1.4)$ & $26.0(15.9)$ & 4 \\
\hline
\end{tabular}

hypocortisolism or GHD could be confirmed by the criteria mentioned above (Table 2). Statistically, there was no difference in age, sex, BMI, MRS at admittance, and lowest blood glucose in the ITT in both groups. Of the 38 patients tested supine, two had capillary glucose levels $>40 \mathrm{mg} / \mathrm{dl}(>2.2 \mathrm{mmol} / \mathrm{l})$ ( 45 and $47 \mathrm{mg} / \mathrm{dl}$ or 2.5 and $2.6 \mathrm{mmol} / \mathrm{l}$ respectively); one of these two patients showed lower cortisol values and was suspected of hypocortisolism. In the group of patients tested in a sitting position, five patients revealed capillary blood glucose levels $\geq 40 \mathrm{mg} / \mathrm{dl}(>2.2 \mathrm{mmol} / \mathrm{l})(40 \mathrm{mg} / \mathrm{dl}$, $42 \mathrm{mg} / \mathrm{dl}, 45 \mathrm{mg} / \mathrm{dl}(2 \times), 46 \mathrm{mg} / \mathrm{dl}$ or $2.2 \mathrm{mmol} / \mathrm{l}$, $2.3 \mathrm{mmol} / \mathrm{l}, 2.5 \mathrm{mmol} / \mathrm{l}(2 \times)$, and $2.6 \mathrm{mmol} / \mathrm{l}$ respectively), none of them showed hormonal disturbances. Since in most patients the serum glucose level, which was measured for dual control, dropped to $<40 \mathrm{mg} / \mathrm{dl}$ $(<2.2 \mathrm{mmol} / \mathrm{l})$ and all patients showed clinically strong signs of hypoglycemia, no patient was excluded from the observational report.

A low age-related IGF1 level was measured in $16 \%(6 / 38$ patients) of the patients tested supine; in $84 \%$ of these patients, a low IGF1 level corresponded with GHD. In $29 \%$ of the patients tested supine, GHD was not indicated by lowered IGF1 levels. Similar to the patients tested supine, $16.7 \%$ of the patients tested in a sitting position (3/18 patients) revealed low age-related IGF1 levels, but in none of them, GHD was confirmed with the ITT. In $16.7 \%$ of the patients tested in a sitting position, GHD was not indicated by lowered IGF1 levels.

Patients tested supine showed a lower $\mathrm{GH}$ peak in the ITT (median $4.9 \mu \mathrm{g} / \mathrm{l}(0.23 \mathrm{nmol} / \mathrm{l})$, minimum $0.1 \mu \mathrm{g} / \mathrm{l}$ $(0.0047 \mathrm{nmol} / \mathrm{l})$, maximum $46 \mu \mathrm{g} / \mathrm{l}(2.14 \mathrm{nmol} / \mathrm{l}))$ than patients tested in a sitting position (median $8.7 \mu \mathrm{g} / \mathrm{l}$ $(0.405 \mathrm{nmol} / \mathrm{l})$, minimum $1.4 \mu \mathrm{g} / \mathrm{l}(0.065 \mathrm{nmol} / \mathrm{l})$, maximum $30 \mu \mathrm{g} / \mathrm{l}(1.395 \mathrm{nmol} / \mathrm{l})$; Fig. 1a). As shown in Fig. 1b, not only GH peak levels, but also cortisol peak levels in the ITT were lower in patients tested supine (median $16.8 \mu \mathrm{g} / \mathrm{dl}(464 \mathrm{nmol} / \mathrm{l})$, minimum $8.6 \mu \mathrm{g} / \mathrm{dl}$ $(237 \mathrm{nmol} / \mathrm{l})$, maximum $38.3 \mu \mathrm{g} / \mathrm{dl}(1057 \mathrm{nmol} / \mathrm{l})$ ) than in patients tested in a sitting position (median $23.1 \mu \mathrm{g} / \mathrm{dl} \quad(638 \mathrm{nmol} / \mathrm{l})$, minimum $18.1 \mu \mathrm{g} / \mathrm{dl}$ (500 nmol/l), maximum $32.8 \mu \mathrm{g} / \mathrm{l}(905 \mathrm{nmol} / \mathrm{l})$ ). 

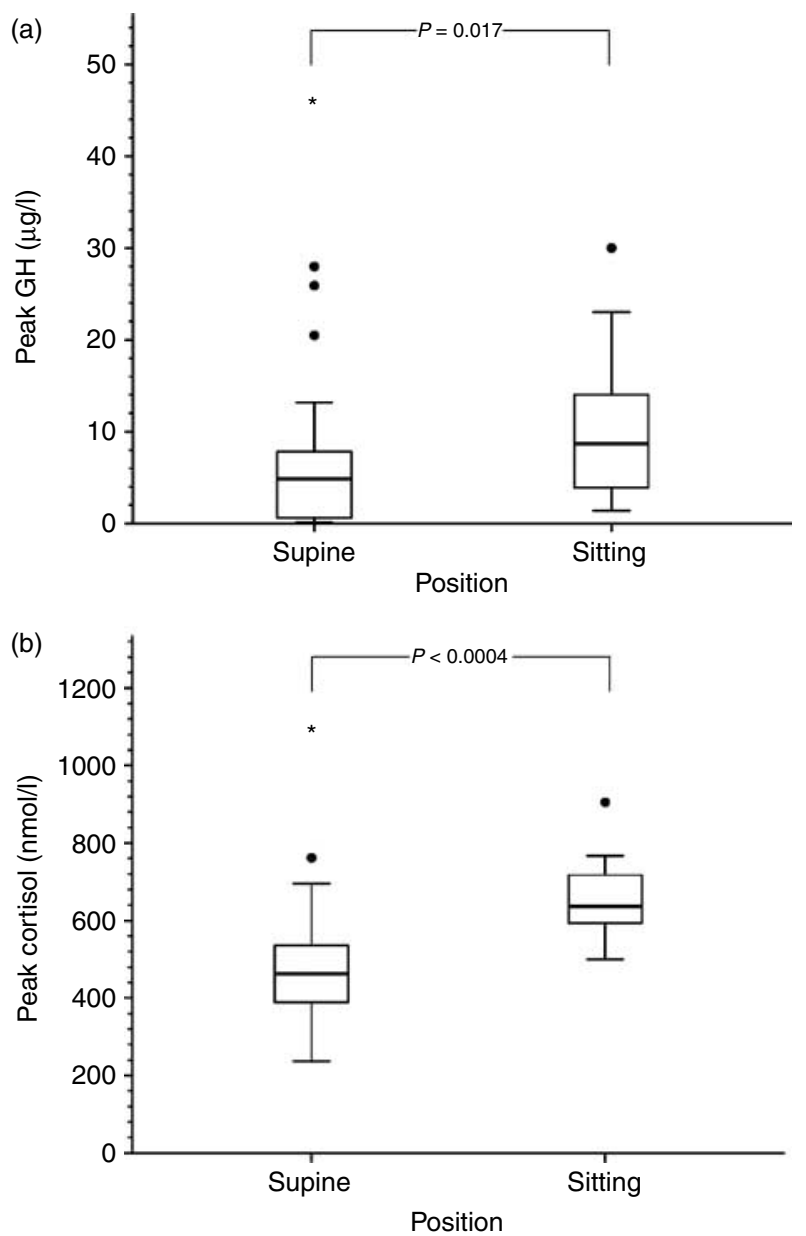

Figure $1 \mathrm{GH}$ peak (a) and cortisol peak (b) in the insulin tolerance test in patients tested supine and in a sitting position; the central box covers the interquartile range, the median is indicated by the line within the box, whiskers extend to the most extreme values within 1.5 interquartile ranges of the quartiles, more extreme values are plotted individually as points or in case of extreme outliers as stars respectively. Statistical analyses were performed with the Mann-Whitney $U$ test.

\section{Symptoms}

Patients in a sitting position suffered from symptoms of the sympathetic nervous system such as tachycardia $(61.1 \%$ sitting versus $15.8 \%$ supine, $P=0.001)$, trembling $(22.2 \%$ sitting versus $7.9 \%$ supine, NS), and sweating $(66.7 \%$ sitting versus $28.9 \%$ supine, $P=0.007$; Fig. 2a). There was no significant difference in declaring central nervous symptoms such as drowsiness $(72.2 \%$ sitting versus $65.8 \%$ supine, NS) and dizziness $(44.4 \%$ sitting versus $44.7 \%$ supine, NS; Fig. 2b). Because of somnolence induced by hypoglycemia in the ITT, the hypoglycemic state could not be stopped by food intake but only with i.v. administration of glucose in 25 supine patients ( 25 of 38 patients $(66 \%)$ tested supine versus 0 of 18 patients $(0 \%)$ tested in a sitting position, $P<0.0001)$. Of these 25 patients treated with a glucose solution, $15(60 \%)$ showed hormonal disturbances in the ITT (ten patients with GHD in combination with hypocortisolism, one patient with GHD, and four patients with hypocortisolism). In 13 patients tested supine, no glucose infusion was necessary to normalize the blood glucose level. Of these 13 patients, eight $(61.5 \%)$ showed hormonal insufficiencies. GHD in combination with hypocortisolism was diagnosed in four patients; in another four patients, hypocortisolism was diagnosed as single hormonal disturbance. Testing patients in a sitting position, all patients were able to intake food by themselves, and none of these patients got somnolent.

No epileptic seizure occurred during the tests in all 56 patients.

\section{Discussion}

We found that patients tested supine in the ITT showed significantly less adrenergic signs such as trembling, tachycardia, and sweating than patients tested in a sitting position. Furthermore, most supine patients got somnolent during the ITT. Hypocortisolism and GHD were significantly more often diagnosed in patients tested supine.
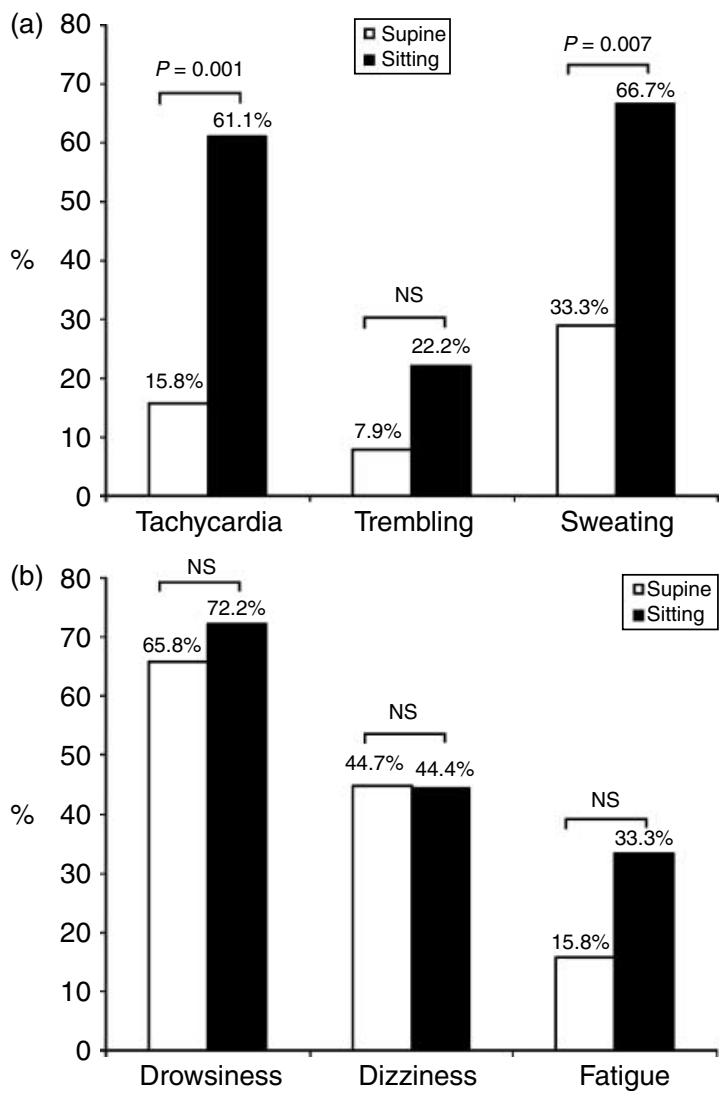

Figure 2 Adrenergic symptoms (a) and symptoms attributed to the central nervous system (b) during hypoglycemia in the insulin tolerance test assessed by Pearson $\chi^{2}$ and by Fisher's exact test. 
Physiologically, posture has a significant influence on vigilance and arousal reaction $(12,13)$, which is well known and applied daily, e.g. in rehabilitation therapy $(14,15)$. Vigilance and arousal reactions are mainly influenced by the brain stem areas such as the ascending reticular activating system, which is connected to the hypothalamic regions. In patients with brain damage as TBI or SAH, neuronal structures like the hypothalamus, the thalamus, the pituitary gland and the brain stem are often affected. This damage might lead to a lower stimulation of the hypothalamus and impair catecholamine release since the ventromedial hypothalamus is responsible for the release of catecholamines in hypoglycemia $(16,17)$.

Additionally, most patients tested supine got somnolent during the test. Thus, the hypoglycemic state had to be terminated by i.v. administration of glucose. Even if the aim of attaining a blood glucose level lower than $40 \mathrm{mg} / \mathrm{dl}(<2.2 \mathrm{mmol} / \mathrm{l})$ was reached, the time to maintain this low level was probably too short and the normalization was too rapid to adequately stimulate the corticotrop/somatotrop axis. This could explain the high rate of hypocortisolism and GHD in patients tested supine possibly as false positive results. Retesting of patients in a sitting position could not confirm the diagnosis.

In line with our observations, Nye et al. (18) reported that the maximum cortisol level in the ITT depended on the duration of hypoglycemia. The influence of glucose applied during the hypoglycemic state in the ITT is discussed controversially in the literature (19, 20); therefore, a significant influence on the result of the ITT cannot safely be ruled out.

Since we present observations in the ITT while performing our screening program, our analysis has several limitations to be addressed. First of all, we did not perform ITT in supine and sitting positions in all subjects, and in those subjects in whom this was performed, the delay between the two tests was sometimes large. Hence, our findings must be considered observational. Potential alternative explanations for our findings are true differences in rates of hypopituitarism among groups and spontaneous recovery of pituitary function in those subjects retested. Even though, we cannot rule out these alternative explanations, such an unequal distribution in rates of pituitary deficits seems unusual, given the similar group characteristics. And, though spontaneous regeneration of the pituitary gland is possible, it is unlikely that the diagnosis of hypopituitarism could not be verified in even one patient (3-5).

In order to confirm our hypothesis, further investigations are necessary, such as a cross-over study or randomized study with patients after TBI or SAH and healthy controls. When the ITT was first applied in 1966, control subjects (7) and patients with hypothalamic or pituitary dysfunction (8) were tested in a horizontal position, at least before the first blood sample was drawn. But none of them suffered from brain damage as TBI or SAH.

Of note is that our results may partly explain the high variation in rates of hypopituitarism in patients with TBI and SAH in different studies, attributing them to the variance of SOP used.

\section{Declaration of interest}

The authors declare that there is no conflict of interest that could be perceived as prejudicing the impartiality of the research reported.

\section{Funding}

This work was part of the project 'Patients after traumatic brain injury or subarachnoid hemorrhage - screening for hypopituitarism' (project number NRA 6280051), which was supported by an unrestricted grant from Pfizer GmbH, Germany.

\section{Acknowledgements}

We thank B Schäpers for help in data assessment and in the performance of the ITT and I Kilimann for the performance of ITT in supine position.

\section{References}

1 Schneider HJ, Aimaretti G, Kreitschmann-Andermahr I, Stalla GK \& Ghigo E. Hypopituitarism. Lancet 2007369 1461-1470. (doi:10.1016/S0140-6736(07)60673-4)

2 Berg C, Oeffner A, Schumm-Draeger PM, Badorrek F, Brabant G, Gerbert B, Bornstein S, Zimmermann A, Weber M, BroeckerPreuss M, Mann K \& Herrmann BL. Prevalence of anterior pituitary dysfunction in patients following traumatic brain injury in a German multi-centre screening program. Experimental and Clinical Endocrinology and Diabetes 2010 118 139-144. (doi:10. 1055/s-0029-1225611)

3 Schneider HJ, Kreitschmann-Andermahr I, Ghigo E, Stalla GK \& Agha A. Hypothalamopituitary dysfunction following traumatic brain injury and aneurysmal subarachnoid hemorrhage: a systematic review. Journal of the American Medical Association 2007298 1429-1438. (doi:10.1001/jama.298.12.1429)

4 Schneider HJ, Schneider M, Saller B, Petersenn S, Uhr M, Husemann B, von Rosen F \& Stalla GK. Prevalence of anterior pituitary insufficiency 3 and 12 months after traumatic brain injury. European Journal of Endocrinology $2006154259-265$. (doi:10.1530/eje.1.02071)

5 Tanriverdi F, Senyurek H, Unluhizarci K, Selcuklu A, Casanueva FF \& Kelestimur F. High risk of hypopituitarism after traumatic brain injury: a prospective investigation of anterior pituitary function in the acute phase and 12 months after trauma. Journal of Clinical Endocrinology and Metabolism $2006 \mathbf{9 1}$ 2105-2111. (doi:10.1210/jc.2005-2476)

6 Hoffman DM, Nguyen TV, O’Sullivan AJ, Baxter RC \& Ho KK. Diagnosis of growth hormone deficiency in adults. Lancet 1994 344 482-483. (doi:10.1016/S0140-6736(94)91821-X)

7 Greenwood FC, Landon J \& Stamp TC. The plasma sugar, free fatty acid, cortisol, and growth hormone response to insulin. I. In control subjects. Journal of Clinical Investigation 1966 45 429-436. (doi:10.1172/JCI105357)

8 Landon J, Greenwood FC, Stamp TC \& Wynn V. The plasma sugar, free fatty acid, cortisol, and growth hormone response to insulin, and the comparison of this procedure with other tests of 
pituitary and adrenal function. II. In patients with hypothalamic or pituitary dysfunction or anorexia nervosa. Journal of Clinical Investigation 196645 437-449. (doi:10.1172/JCI105358)

9 Kokshoorn NE, Wassenaar MJ, Biermasz NR, Roelfsema F, Smit JW, Romijn JA \& Pereira AM. Hypopituitarism following traumatic brain injury: prevalence is affected by the use of different dynamic tests and different normal values. European Journal of Endocrinology 2010162 11-18. (doi:10.1530/EJE-09-0601)

10 van Swieten JC, Koudstaal PJ, Visser MC, Schouten HJ \& van Gijn J. Interobserver agreement for the assessment of handicap in stroke patients. Stroke $198819604-607$.

11 Brabant G, von zur Muhlen A, Wuster C, Ranke MB, Kratzsch J, Kiess W, Ketelslegers JM, Wilhelmsen L, Hulthen L, Saller B, Mattsson A, Wilde J, Schemer R \& Kann P. Serum insulin-like growth factor I reference values for an automated chemiluminescence immunoassay system: results from a multicenter study. Hormone Research 200360 53-60. (doi:10.1159/000071871)

12 Skinner RD, Homma Y \& Garcia-Rill E. Arousal mechanisms related to posture and locomotion: 2. Ascending modulation. Progress in Brain Research 2004143 291-298. (doi:10.1016/ S0079-6123(03)43028-8)

13 Horne RS, Franco P, Adamson TM, Groswasser J \& Kahn A. Effects of body position on sleep and arousal characteristics in infants. Early Human Development 200269 25-33. (doi:10.1016/S03783782(02)00025-7)

14 Greenwald BD \& Rigg JL. Neurorehabilitation in traumatic brain injury: does it make a difference? Mount Sinai Journal of Medicine 200976 182-189. (doi:10.1002/msj.20103)

15 Luther MS, Krewer C, Muller F \& Koenig E. Comparison of orthostatic reactions of patients still unconscious within the first three months of brain injury on a tilt table with and without integrated stepping. A prospective, randomized crossover pilot trial. Clinical Rehabilitation 200822 1034-1041. (doi:10.1177/ 0269215508092821)

16 Borg WP, During MJ, Sherwin RS, Borg MA, Brines ML \& Shulman GI. Ventromedial hypothalamic lesions in rats suppress counterregulatory responses to hypoglycemia. Journal of Clinical Investigation 199493 1677-1682. (doi:10.1172/JCI117150)

17 Routh VH. Glucose-sensing neurons: are they physiologically relevant? Physiology \& Behavior 200276 403-413. (doi:10. 1016/S0031-9384(02)00761-8)

18 Nye EJ, Grice JE, Hockings GI, Strakosch CR, Crosbie GV, Walters MM, Torpy DJ \& Jackson RV. The insulin hypoglycemia test: hypoglycemic criteria and reproducibility. Journal of Neuroendocrinology 200113 524-530. (doi:10.1046/j.13652826.2001.00664.x)

19 Borm K, Slawik M, Beuschlein F, Seiler L, Flohr F, Berg A, Koenig A \& Reincke M. Low-dose glucose infusion after achieving critical hypoglycemia during insulin tolerance testing: effects on time of hypoglycemia, neuroendocrine stress response and patient's discomfort in a pilot study. European Journal of Endocrinology 2005153 521-526. (doi:10.1530/eje.1.01992)

20 Yeste D, Tomasini R, Dodino G, Gussinye M, Potau N \& Carrascosa A. Hypoglycaemia-insulin test: discordant growth hormone and cortisol response in paediatric patients regarding recovery from hypoglycaemia with or without oral glucose solution. Hormone Research 200767 42-45. (doi:10.1159/000096055)

Received 11 October 2010

Accepted 27 October 2010 